\title{
CALIBRATION OF THE DUCTILE FAILURE CRITERION FOR NICKEL-BASED SUPERALLOYS TAKING INTO ACCOUNT THE LOCALIZATION OF THE STRAIN
}

\author{
Bartosz Madejski, Grzegorz Socha \\ Institute of Aviation, Warsaw, Poland
}

\begin{abstract}
Static tension test allows characterization of material strength properties. This simple test provides input data for numerical calculation of structural components made of the tested alloy. Elastic, plastic and failure behavior of the structural component in question is simulated, using, for example, the FEM package, based on parameters obtained as the result of tensile testing. When using the results of the tensile test for modeling the material failure it is important to estimate correctly plastic strain corresponding to failure. It is common practice to use elongation of the specimen gage part for the calculation of failure strain. On the other side, the most popular ductile failure criterion used by engineers performing numerical simulation of the material's behavior relies on the equivalent plastic strain as the criterial quantity. Those two parameters can differ significantly. In order to calculate the equivalent plastic strain correctly, we have to remember about strain localization (necking) appearing during tensile tests and take into account the fact that during tensile testing we have three non-zero strain tensor components. Ignoring this fact, and using only elongation as the criterial quantity can lead to enormous simulation error. This error is analyzed in this paper for nickel based superalloy tested at elevated temperatures.
\end{abstract}

Keywords: equivalent plastic strain, tensile test, failure criterion.

\section{INTRODUCTION}

There are many ductile failure criteria allowing the modeling of failure of ductile materials such as metal alloys. The most frequently used one is the constant equivalent plastic strain criterion. According to this criterion, fracture occurs in a material when the equivalent plastic strain reaches a critical value:

where

$$
\bar{\varepsilon}^{p}=\bar{\varepsilon}_{f}^{p}
$$

$\bar{\varepsilon}_{f}^{p}$-accumulated equivalent plastic strain corresponding to material failure $\bar{\varepsilon}^{p}$ - equivalent plastic strain 
This criterion, however simple and easy to use, was not confirmed by experiments. The classic experiment by von Karman [1] showed that marble and sandstone exhibiting brittle fracture under simple, uniaxial compression (no plastic strain before failure can be observed) could achieve significant plastic deformation when subjected to high hydrostatic pressure. This experimental observation led to the modification of the ductile failure criterion (1). A number of modified criteria, relating accumulated failure strain to stress state were formulated. One of them, used by many researchers was proposed by Johnson and Cook [2]. If the strain rate and temperature are constant, the strain to fracture is a monotonic function of the stress triaxiality, as shown in the equation bellow:

$$
\bar{\varepsilon}_{f}=C_{1}+C_{2} \exp \left(C_{3} \eta\right)
$$

where $\eta$ (stress triaxiality parameter) is a ratio of the mean stress to equivalent stress

$$
\eta=\frac{\sigma_{m}}{\bar{\sigma}} .
$$

This criterion (2) was further modified [3,4] to better fit experimental data. A good review of the ductile failure models was given in paper [5].

Another approach, typically used in the case of brittle fracture, is the stress approach. One of the most popular from this group is the maximum shear (MS) stress criterion. From this criterion, it follows that fracture may occur on a plane where the shear stress is maximum. In view of this fact, fracture is governed by the condition:

where

$$
\tau_{\max }=\left(\tau_{\max }\right) \text { and } \sigma_{1}, \sigma_{2}, \sigma_{3}
$$

$$
\tau_{\max }=\max \left\{\frac{\sigma_{1}-\sigma_{2}}{2}, \frac{\sigma_{2}-\sigma_{3}}{2}, \frac{\sigma_{3}-\sigma_{1}}{2}\right\}
$$

In the case of metal alloys exhibiting elastic - plastic behavior, ductile failure can be expected for most stress states. In this case, we should use the strain approach (ductile failure criterion). Determining failure strain (equivalent plastic strain) using static tension we should remember about the fact, that elongation calculated according to standard [6], [7], [8] and [9] is an average value of deformation of the specimen gage part, and that strain localization occurrence leads to formation non-uniform stress and strain distribution in the cohesive zone (neck). The present paper is concerned with error which can appear when we estimate the critical (corresponding to failure) value of equivalent plastic strain using static tensile tests while disregarding the localization of strain. 


\section{MATERIAL AND EXPERIMENTAL TECHNIQUE}

The material used for the tests was nickel alloy. Nickel alloys are characterized by high mechanical properties and corrosion resistance at elevated temperatures. For these reasons, they are widely used in the aviation and nuclear industries, especially in gas turbines, jet engines and other components working in extreme conditions. For our tests, we used two different alloys. One was INCONEL 718, which is characterized by high ductility. The other was nickel alloy in the form of the cast, which is very brittle and exhibits low ductility. Table 1 shows the chemical compositions of INCONEL 718. The chemical composition of the other alloy is not permitted to be published.

Table 1. Chemical composition [\% weight] - INCONEL 718

\begin{tabular}{|c|c|c|c|c|c|c|c|}
\hline $\mathbf{C}$ & $\mathbf{M n}$ & $\mathbf{P}$ & $\mathbf{S}$ & $\mathbf{S i}$ & $\mathbf{C r}$ & $\mathbf{N i}$ & $\mathbf{A l}$ \\
\hline 0,03 & 0,08 & 0,01 & 0,0005 & 0,09 & 18,49 & 52,92 & 0,6 \\
\hline & & & & & & & \\
\hline $\mathrm{Mo}$ & $\mathrm{Cu}$ & $\mathrm{Nb}$ & $\mathrm{Ta}$ & $\mathrm{Ti}$ & $\mathrm{Co}$ & $\mathrm{B}$ & $\mathrm{Fe}$ \\
\hline 2,88 & 0,04 & 5,12 & 0,01 & 0,86 & 0,27 & 0,004 & 18,39 \\
\hline
\end{tabular}

The tensile tests were carried out according to ASTME8/E8M-16a and ASTM E21-09. 21 and 138 specimens were tested for INCONEL 718 and nickel alloy (cast), respectively. Table 2 shows more details regarding the testing program. For all tensile tests, specimens designed according to the ASTM E8M-16a requirements were used. The drawing of the specimen is shown in Fig. 1.

Table 2. Test plan for two nickel alloys

\begin{tabular}{|c|c|c|c|c|}
\hline \multicolumn{2}{|c|}{ INCONEL 718 } & & \multicolumn{2}{c|}{ Nickel alloy - cast } \\
\hline $\begin{array}{c}\text { Temperatures } \\
\text { of the tests [F] }\end{array}$ & $\begin{array}{c}\text { Number of tested } \\
\text { specimens }\end{array}$ & & $\begin{array}{c}\text { Temperatures } \\
\text { of the tests [F] }\end{array}$ & $\begin{array}{c}\text { Number of tested } \\
\text { specimens }\end{array}$ \\
\hline 75 & 12 & & 75 & 16 \\
\hline 400 & 1 & & 1022 & 16 \\
\hline 750 & 6 & 1202 & 16 \\
\hline 1100 & 1 & 1292 & 16 \\
\hline 1300 & 1 & & 1382 & 16 \\
\hline & & & 1572 & 16 \\
\hline & & & 1652 & 16 \\
\hline & & & 1742 & 10 \\
\hline
\end{tabular}




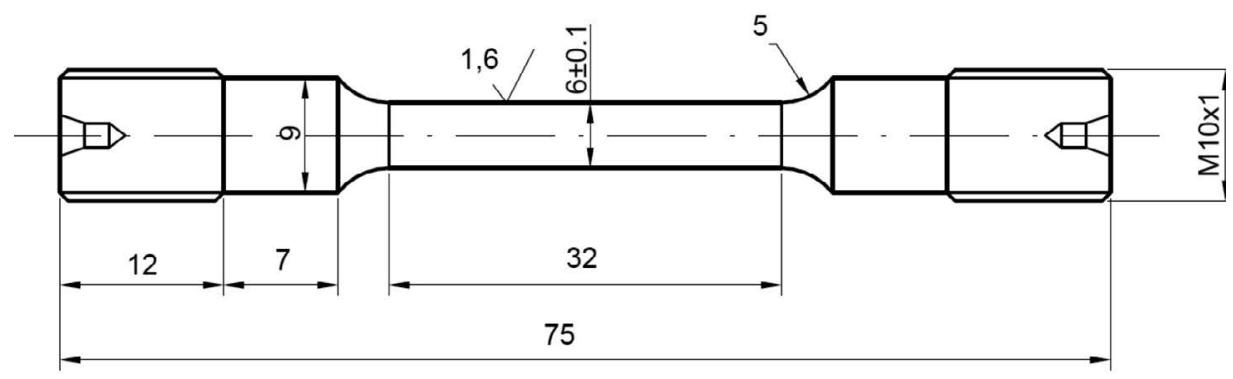

Fig. 1. Specimen used in tensile tests (according ASTM E8M-16a).

For tensile tests, the servo hydraulic machines MTS 318.10 with load capacity $\pm 100 \mathrm{kN}$ were used. The machine (Fig. 2) was equipped with the furnace (INSTRON SFL mod 3812K control system) with three heating zones and an extensometer MTS mod 63253F-14. During the tests, temperature was measured using three type $\mathrm{S}$ thermocouples connected with the control system and furnace.

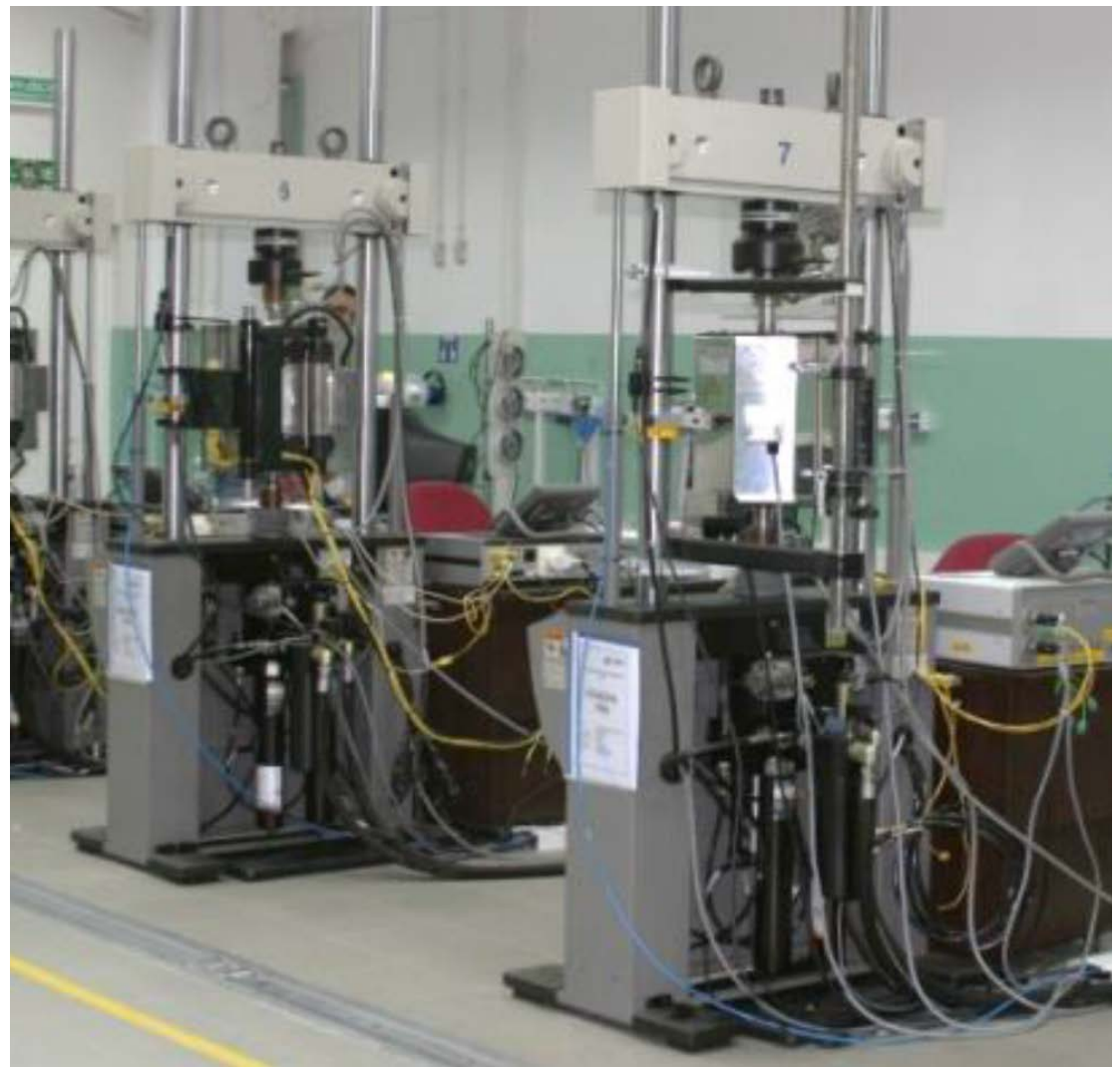

Fig. 2. Testing machines 
The tensile tests were carried out according to the ASTM and ISO standards. For all specimens, standard elongation (according to the ASTM E8/E8M-16a and PN-EN ISO 6892-1:2016-09) was calculated. Standard elongation for specimens with the gauge length equal five times the diameter was marked as $E l(A 5)$.

During the tensile test, the specimen's gage part is initially deformed in the elastic regime. After reaching the yield limit, plastic deformation starts to develop in the gage part of the specimen. The test specimen is strained uniformly along its gage part length up to the point of maximum force. This means that the gage section gets longer and thinner but keeps its cylindrical shape. As soon as the maximum force is reached a neck begins to form in the gage part of the specimen. All further plastic deformation develops only at the neck since strain hardening cannot compensate the reduction of the neck cross-section area any more. This fact has important consequences. When calculating the final equivalent plastic strain corresponding to material failure it is necessary to take into account the strain localization. In order to estimate correctly this value, we have to take into account a reduction of the area, which is more pronounced for alloys with high ductility (Figure 3b), but hardly detectable for brittle alloys (Figure 3c).
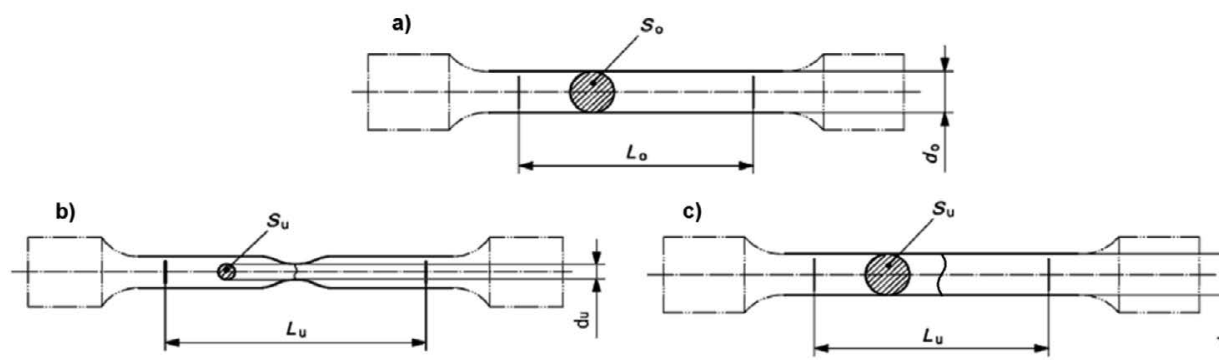

Fig. 3. Shape of the specimens: a) before tensile test, b) after tensile tests for ductile alloy, c) after tensile tests for brittle alloy

For all specimens, final equivalent plastic strain was calculated for the smallest cross-section of the neck. Transversal plastic strain for this cross-section was calculated using measurements of the specimen's diameter before and after the test. Assuming plastic isotropy and incompressibility of the material, two other principal plastic strains were calculated using the simple formula:

$$
\varepsilon^{p}{ }_{y}=\varepsilon^{p}{ }_{z}=-\frac{1}{2} \varepsilon^{p}{ }_{x}
$$

The equivalent plastic strain is the function of three principal strains $\left(\varepsilon_{\mathrm{x}}, \varepsilon_{\mathrm{y}}, \varepsilon_{\mathrm{z}}\right)$ as defined below: 


$$
\varepsilon^{p}=\frac{\sqrt{2}}{3} \sqrt{\left(\varepsilon_{x}^{p}-\varepsilon_{y}^{p}\right)^{2}+\left(\varepsilon_{y}^{p}-\varepsilon_{z}^{p}\right)^{2}+\left(\varepsilon_{z}^{p}-\varepsilon_{x}^{p}\right)^{2}}
$$

Taking into account relation (6) we can calculate the final equivalent strain using following formula:

$$
\varepsilon^{p}=\frac{\sqrt{2}}{3} \sqrt{\left(-2 \varepsilon_{y}^{p}-\varepsilon_{y}^{p}\right)^{2}+\left(\varepsilon_{y}^{p}-\varepsilon_{y}^{p}\right)^{2}+\left(\varepsilon_{y}^{p}+2 \varepsilon_{y}^{p}\right)^{2}}=2 \varepsilon_{y}^{p}
$$

It is worth to note that the equivalent plastic strain in the case of simple tension has the value equal to the value of axial strain in the direction of the force. The value of standard elongation $\mathrm{El}(\mathrm{A5})$ was calculated according to the ASTM E8/ E8M-16a standard. According the ASTM standard, gauge lengths markings of the test specimens were made before tensile tests. After tensile tests, two halves of specimens fractures were fit together and the distance between the gage part was measured. In order to calculate elongation, the following formula was used:

$$
E l(A 5)=\frac{\Delta L}{L_{0}}=\frac{L-L_{0}}{L_{0}} .
$$

\section{RESULTS AND DISCUSSION}

Standard elongation $E l(A 5)$ and the final equivalent plastic strain are plotted as the function of test temperature in Figure 4, for nickel cast alloy. This alloy is characterized by low ductility, especially at room temperature. For these specimens, the fracture is brittle so the neck does not appear. Only at higher temperatures the ductility is higher and we can observe the formation of a neck.

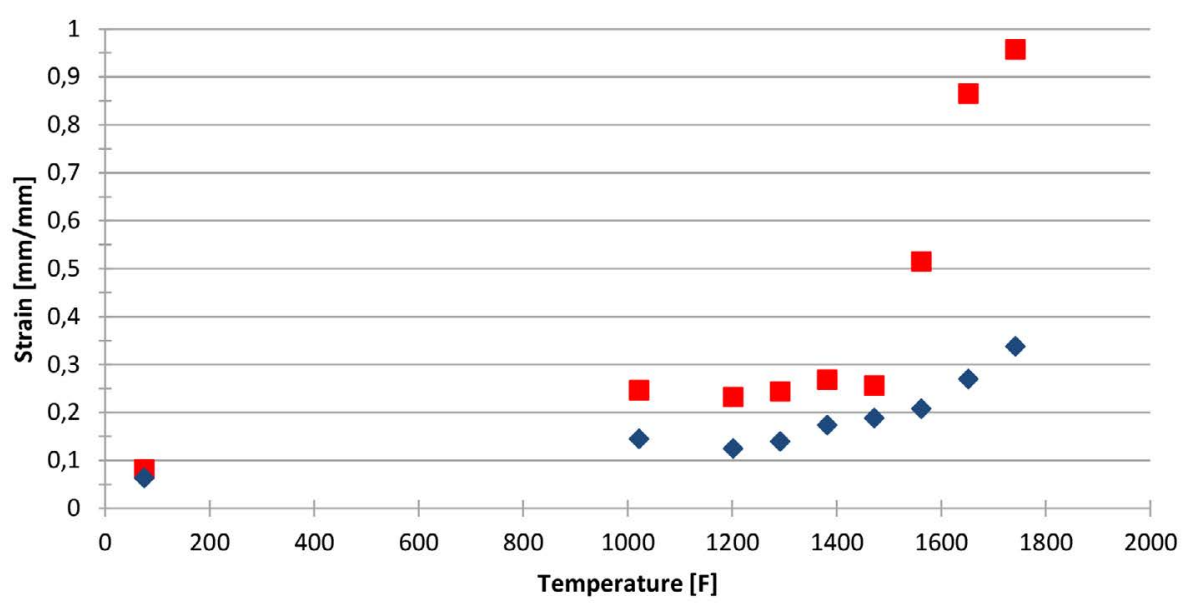

Fig. 4. Final equivalent plastic strain ()-marked red, and standardized elongation (El(A5)) - marked blue, for nickel alloy (cast). 
The error of failure strain estimation for all temperatures is shown in Figure 5. It was calculated according to the formula bellow:

$$
\left(\frac{\bar{\varepsilon}_{f}^{p}-E l(A 5)}{\operatorname{El}(A 5)}\right) \times 100 \%
$$

where:

$\bar{\varepsilon}_{f}^{p}$ - final equivalent plastic strain calculated according to formula (8),

$E l(A 5)$ - standard elongation of the specimen's gage part.

If we compare the standard elongation $(E l(A 5))$ and final equivalent plastic strain (), we can notice that the higher the temperature is the higher the error is. This is associated with the ductility of the alloy in question increasing with the temperature. At higher temperatures, the reduction of area is more visible. If we do not take into account the reduction of the area at high temperatures, we will receive huge error of failure strain estimation.

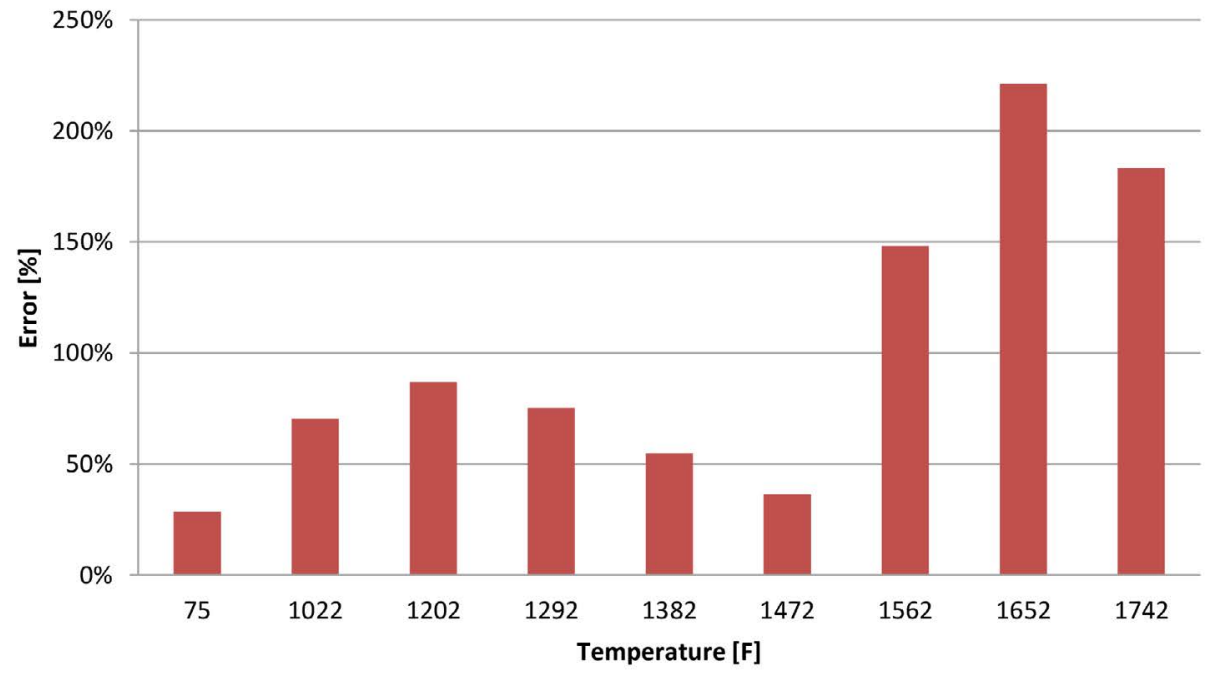

Fig. 5. Error calculated according to formula (10) for nickel alloy (cast).

The second alloy tested was INCONEL 718. The results for this alloy are presented in Figure 6 . This alloy is characterized by high ductility so during tests a typical neck appears in the gage part of the specimen. 


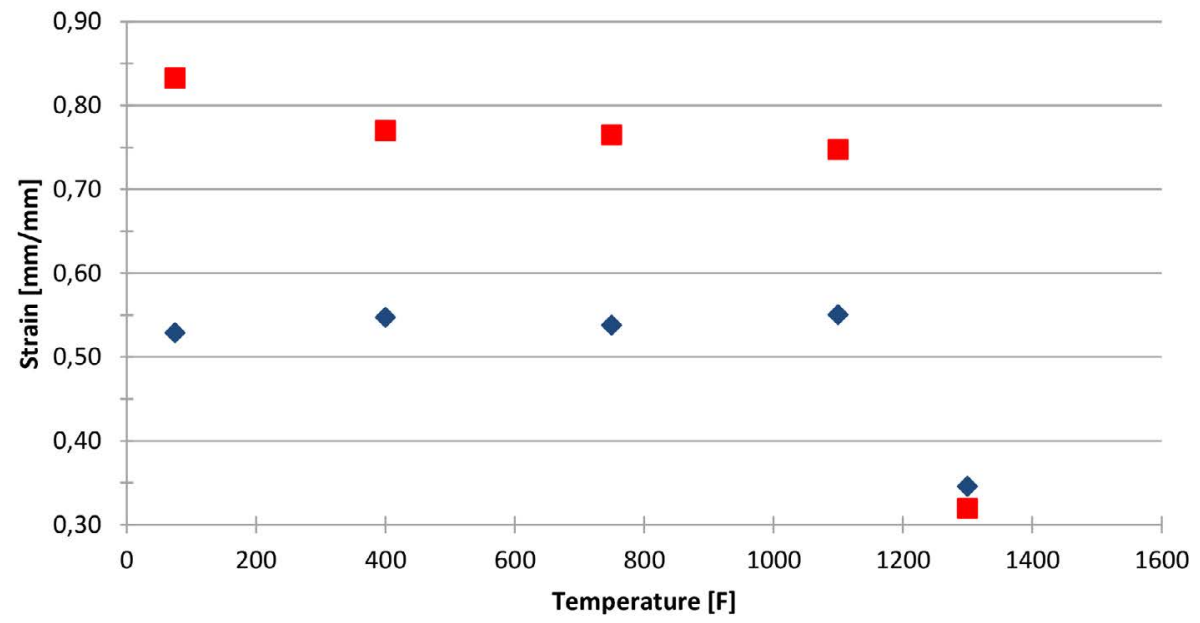

Fig. 6. Equivalent plastic strain () - marked red, and standard elongation (El(A5)) - marked blue, for nickel alloy for INCONEL 718.

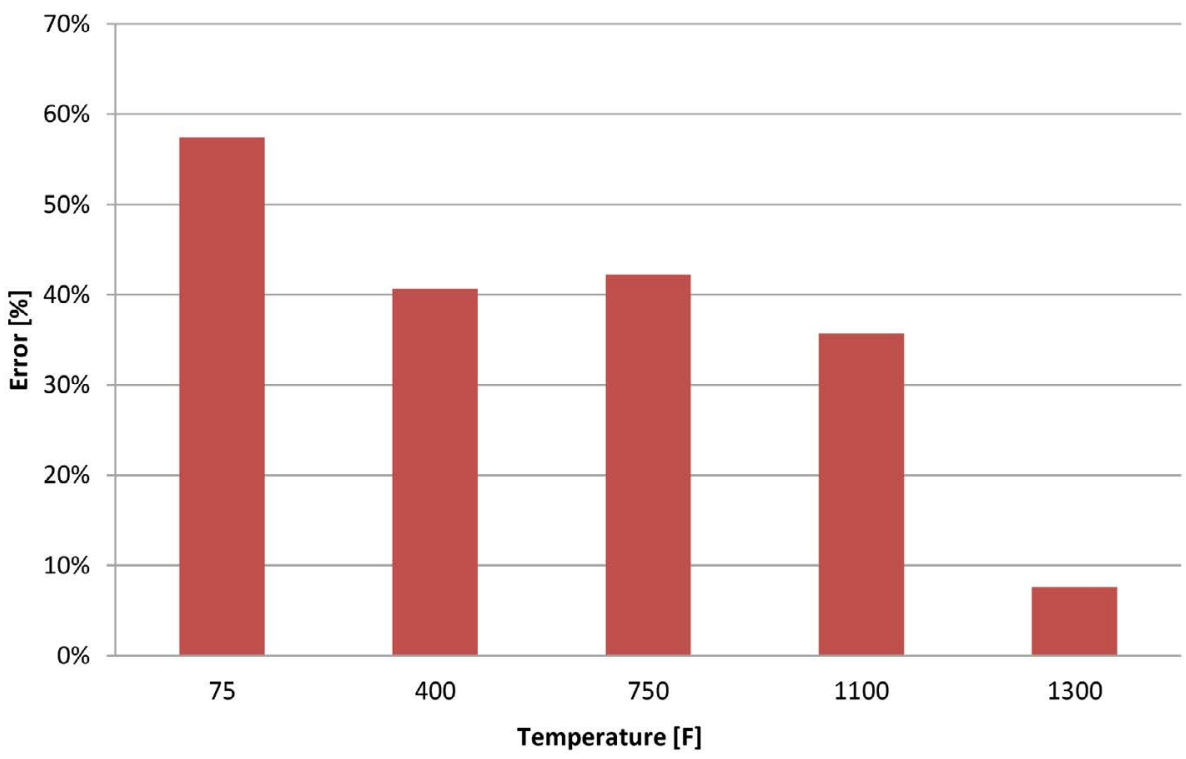

Fig. 7. Error calculated according to formula (10) for INCONEL 718.

In this case, at high temperatures a smaller error of failure strain estimation was obtained as it can be seen in Figure 7. This can be attributed to the ductility decreasing with the rising temperature. If the neck does not appear, as in the case of the test at $1300 \mathrm{~F}$, the reduction of the cross section in the whole gage section is almost the same - see Figure 8b. The error in this case is negligible. At room temperature (Figure 8a), strain localization in the form of the neck is clearly visible. 

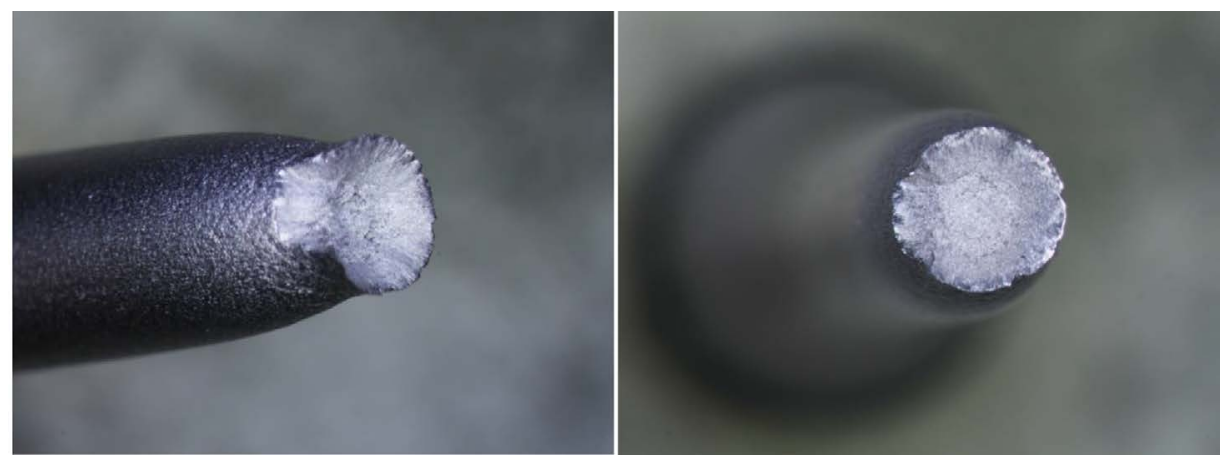

a) room temperature

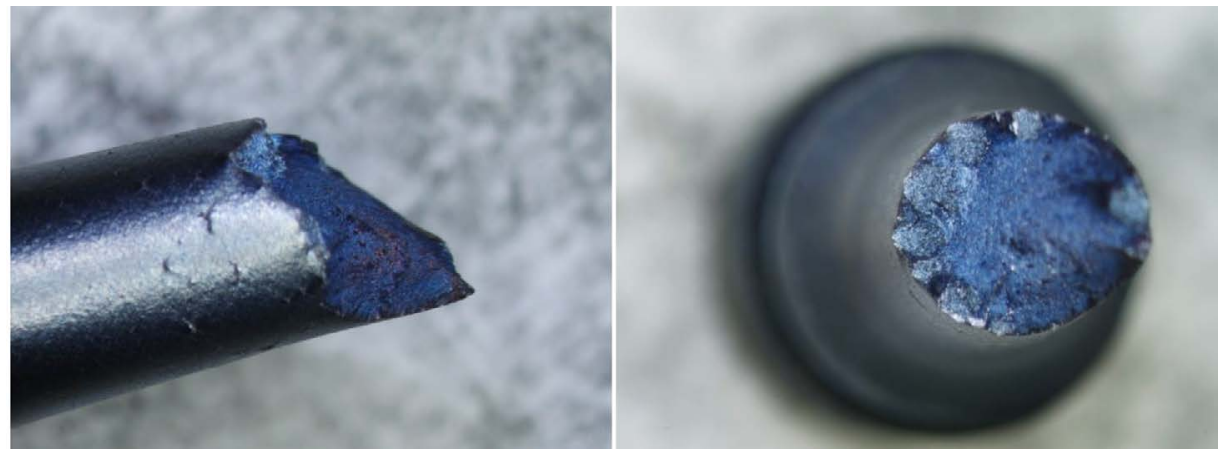

b) $1300 \mathrm{~F}$

Fig.8 Fracture appearance for: (a) room temperature and (b) temperature 1300F for INCONEL 718 alloy

\section{CALCULATION OF FINAL EQUIVALENT PLASTIC STRAIN USING STANDARD STATIC TENSION TEST RESULTS}

As it was proved above, standard elongation $E l(A 5)$ calculated according to standards [6], [7], [8] and [9] should not be used as the value of final equivalent plastic strain in failure condition (1). However, we can calculate the value of the final equivalent plastic strain based on the properly determined results of static tension test. To do this we have to use reduction of the area $(\operatorname{RoA})$, which is calculated according to the standards using the formula below:

$$
\operatorname{Ro} A=\frac{A_{0}-A_{u}}{A_{0}} \cdot 100 \%
$$

where $A_{0}$ stands for the initial value of the cross-section area and $A_{u}$ stands for the final value of the area of the smallest cross-section of the gage part of the specimen. Having measured the smallest diameter of the gage part of the specimen before $\left(d_{0}\right)$ and after $\left(d_{u}\right)$ test we can write: 


$$
R o A=\frac{d_{0}^{2}-d_{u}^{2}}{d_{0}^{2}} \cdot 100 \%=\left(1-\left(\frac{d_{u}}{d_{0}}\right)^{2}\right) \cdot 100 \%
$$

To calculate transversals train using the given reduction of the area, we have to use the following relation:

$$
\varepsilon_{y}^{p}=\frac{d_{0}-d_{u}}{d_{0}}=1-\frac{d_{u}}{d_{0}}
$$

and substituting $\mathrm{d}_{\mathrm{u}} / \mathrm{d}_{0}$ calculated from relation (12)

$$
\varepsilon_{y}^{p}=1-\sqrt{1-\frac{R o A}{100 \%}}
$$

Finally, using equation (8) we can calculate final equivalent plastic strain using the following relation:

$$
\bar{\varepsilon}_{f}^{p}=2 \cdot\left(1-\sqrt{1-\frac{R o A}{100 \%}}\right)
$$

\section{CONCLUSSIONS}

This study led to the following conclusions:

1. When using the results of tensile tests for modeling of material failure it is very important to calculate final equivalent plastic strain properly. The standard elongation cannot be used as the maximum strain the material can reach. Use this simplification will result in large errors of the material ductile failure numerical simulations.

2. The source of this error results from ignoring the localization of the strain (appearance of a neck) in the final phase of the tensile test.

3. For cast alloy, the error increases with increasing ductility of the alloy caused by the temperature rise. For the investigated alloys, the error reached $100 \%$. For standard INCONEL 718 alloy, we can observe the opposite trend: the error decreases with the rise of the temperature due to decreasing ductility.

\section{REFERENCES}

[1] von Karman Th, Festigkeitversuche unter allseitigem Druck,Z. des Ver. Deutsch ingenieurie, 55 (1911), pp. $1794-1757$.

[2] Johnson GR, Cook WH., Fracture characteristics of three metals subjected to various strains, strain rates, temperatures and pressures. Engineering Fracture Mechanics (1985);21(1):31-48.

[3] Cockcroft MG, Latham DJ. Ductility and the workability of metals. Journal of the Institute of Metals, (1968);96:33-9. 
[4] Wilkins ML, Streit RD, Reaugh JE. Cumulative-strain-damage model of ductile fracture: simulation and prediction of engineering fracture tests. Technical Report UCRL-53058, Lawrence Livermore National Laboratory; October 1980.

[5] Tomasz Wierzbicki, Yingbin Bao, Young-Woong Lee, Yuanli Bai. Calibration and evaluation of seven fracture models, Impact and Crash worthiness Laboratory, Massachusetts Institute of Technology.

[6] PN-EN ISO 6892-1:2016-09 - Metale -- Próba rozciągania -- Część 1: Metoda badania w temperaturze pokojowej.

[7] PN-EN ISO 6892-2:2011 - Metale - Próba rozciągania - Część 2: Metoda badania w podwyższonej temperaturze.

[8] ASTM E8/E8M - 16A - Standard Test Methods for Tension Testing of Metallic Materials.

[9] ASTM E21 - 09 - Standard Test Methods for Elevated Temperature Tension Tests of Metallic Materials. 